\title{
VALORIZAÇÃO DO DIREITO DESPORTIVO RESULTANTE DA FORMAÇÃO
}

\section{MEASUREMENT OF THE VALUE OF HOME GROWN PLAYERS' REGISTRATIONS}

\section{VALORIZACIÓN DEL DERECHO DEPORTIVO RESULTANTE DE LA FORMACIÓN}

\author{
SÉRGIO NUNO DA SILVA RAVARA ALMEIDA CRUZ \\ Equiparado a Professor Adjunto Área Científica de Contabilidade do Insitituto Superior de \\ Contabilidade e Administração (ISCA) da Universidade de Aveiro - Portugal \\ sergio.cruz@ua.pt.
}

\section{LUÍS LIMA SANTOS}

Doutor em Ciências Económicas e Empresariais Professor na Escola Superior de Turismo e Tecnologia do Mar - Instituto Politécnico de Leiria - Portugal Ilsantos@ipleiria.pt

\section{GRAÇA MARIA DO CARMO AZEVEDO}

Doutoramento em Gestão - Especialidade em Contabilidade no Instituto Superior da Ciência do Trabalho e da Empresa (ISCTE). Equiparada a Professora Adjunta no Instituto Superior de Contabilidade e Administração da Universidade de Aveiro graca.azevedo@ua.pt.

Observação: A REPeC preservou, neste artigo, a ortografia oriunda de Portugal. Note: REPec preserved in this article the spelling of Portugal.

Observación: La REPeC preservó, en este artículo, la ortografía oriunda de Portugal. 


\section{RESUMO}

O presente artigo trata dos direitos respeitantes a jogadores formados internamente pelas organizações dedicadas ao futebol, às quais podem vir a prestar serviços como desportistas profissionais. O problema reside no facto de os direitos desportivos sobre os referidos jogadores não serem reconhecidos no balanço da entidade formadora, por dificuldades no estabelecimento de um critério fiável de valorização. Considerando o modelo contabilístico vigente, procura-se uma solução que permita o reconhecimento dos direitos desportivos sobre jogadores formados internamente no balanço, a título de activo intangível, com base em critérios fiáveis de valorização. Tendo em vista a valorização fiável dos direitos desportivos respeitantes a jogadores formados internamente, apresenta-se uma solução assente no método dos centros de custo.

Palavras-chave: Contabilidade; Custo de Formação; Direitos Desportivos; Activo Intangível; Valorização Fiável.

\section{ABSTRACT}

This paper deals with the home grown players' registrations by the football organizations in which they can play in a professional status. The main problem to be dealt with relates to the fact that over players' registrations are not recognized in the balance sheet because of the difficulty in establishing reliable criteria to measure them. While adopting the present accounting model, a solution that allows the recognition in the balance sheet of the home grown players' registrations as intangible fixed assets based on reliable measurement criteria is developed. A solution based on the cost centre method is proposed, leading to a reliable measurement of the home grown players' registrations.

Keywords: Accounting; Formation Cost; Players' Registrations; Intangible Fixed Assets; Reliable Measurement.

\section{RESUMEN}

El presente artículo trata de los derechos respectivos a jugadores formados internamente por las organizaciones dedicadas al fútbol, a las cuales pueden venir a prestar servicios como deportistas profesionales. El problema reside en el hecho de que los derechos deportivos sobre los referidos jugadores no sean reconocidos en el balance de la entidad formadora, por dificultades en el establecimiento de un criterio fiable de valorización. Considerando el modelo de contabilidad vigente, se busca una solución que permita el reconocimiento de los derechos deportivos sobre jugadores formados internamente en el balance, a 


\section{repec}

título de activo intangible, con base en criterios fiables de valorización. Teniendo en vista la valorización fiable de los derechos deportivos referentes a jugadores formados internamente, se presenta una solución asentada en el método de los centros de coste.

Palabras clave: Contabilidad; Coste de Formación; Derechos Deportivos; Activo Intangible; Valorización Fiable.

\section{INTRODUÇÃO}

A formação passa por desenvolver aptidões, conhecimentos e capacidades dos jogadores aos mais diversos níveis para que os clubes (clubes e sociedades anónimas desportivas - SAD - que participam em competições profissionais) possam no futuro usufruir dos seus serviços, no sentido de obter bons resultados desportivos e, consequentemente, desempenhos económicos positivos.

Tanto os jogadores formados internamente como aqueles cujos direitos desportivos são adquiridos a terceiras entidades prestam serviços de idêntica natureza, intervindo no desenvolvimento da actividade principal do clube a que estão ligados contratualmente. Além do mais, ambos estão sujeitos ao cumprimento do contrato de trabalho até final deste, ambos possuem capacidade de gerar Benefícios Económicos Futuros (BEF) e ambos podem ser transferidos para outros clubes, mediante contrapartidas financeiras. Principalmente em nível europeu, em termos contabilísticos, a diferença é, todavia, bem visível: os direitos desportivos sobre os jogadores formados internamente não são reconhecidos no balanço, ao contrário dos direitos relativos aos jogadores adquiridos a terceiros.

Consideramos relevante o tema a tratar, ao que acresce ser esta uma área com poucos estudos existentes. Desejamos, pois, dar um modesto contributo para a literatura da especialidade.

O objectivo principal do estudo é demonstrar que o custo histórico é um critério de valorização aplicável ao direito desportivo sobre o jogador formado no próprio clube, possibilitando, assim, o reconhecimento desse direito como activo intangível no balanço desse clube. São objectivos específicos: verificar se o direito desportivo sobre o jogador formado internamente preenche os requisitos necessários para ser reconhecido como activo intangível; demonstrar que a formação de jogadores pelos clubes se equipara em termos contabilísticos a uma actividade de investigação e desenvolvimento (I\&D); propor um modelo de valorização que permita reflectir no balanço o direito desportivo sobre o jogador formado internamente.

O estudo é efectuado através da análise de artigos e livros que versam sobre a matéria em estudo, de normas contabilísticas em vigor e de relatórios e contas dos clubes. Como salientou Johnson (1984) in Bell (1997), a análise de dados documentais é uma fonte de dados extremamente importante. Ao nível da regulação contabilística, baseámo-nos nas normas internacionais de contabilidade do IASB, consagradas pela Comissão das Co- 
munidades Europeias - utilizámos como fonte o Regulamento (CE) n. ${ }^{\circ}$ 1126/2008 de 3 de Novembro (CE, 2008), que substituiu o Regulamento (CE) n. ${ }^{\circ} 1725 / 2003$ - e na Estrutura Conceptual (EC) do IASB. Em termos de relatórios e contas analisámos apenas os disponíveis nos websites de alguns clubes europeus, referentes à época desportiva 2007/2008, que se encontravam no Dow Jones STOXX® Football (2009), por prepararem e elaborarem as demonstrações financeiras (DF) de acordo com as IAS/IFRS da UE; e os referentes a clubes brasileiros que participaram na principal prova nacional no ano 2008.

\section{ENQUADRAMENTO E CARACTERIZAÇÃO DO DIREITO DESPORTIVO NO ÂMBITO DOS ACTIVOS}

Neste ponto inicial, definimos o conceito de direito desportivo sobre o jogador e efectuamos o seu enquadramento no conceito de activo.

\subsection{Conceito de direito desportivo sobre o jogador}

No âmbito do presente estudo, afirmar que "os recursos humanos são os principais activos" é, sem dúvida, oportuno, sobretudo nos clubes cuja finalidade é a participação em competições desportivas de carácter profissional e que necessitam de dispor de um conjunto de jogadores adequado ao desenvolvimento da sua actividade. Estes são os principais agentes, os elementos imprescindíveis à realização dos eventos desportivos.

A utilização do jogador pelos clubes requer que estes detenham o respectivo direito desportivo, também denominado de direito federativo. De acordo com Teresa Nadal (2008, p. 43), o direito desportivo "pode ser entendido como aquele que nasce de um acordo entre uma entidade desportiva e um desportista e que faculta à primeira a inscrição do segundo numa competição em nome e representação da dita entidade". Ou seja, os direitos desportivos "decorrem do registro do contrato de trabalho desportivo atleta/clube na entidade desportiva diretiva da modalidade respectiva gerando um vínculo desportivo" (FILHO, 2008, p. 36). O registro do direito desportivo sobre o jogador em nome de um clube é condição sine qua non para que o atleta possa disputar provas oficiais, funcionado, portanto, como uma licença para o clube utilizar o jogador (RODRIGUES, 2008). Unicamente os clubes podem ser originariamente titulares destes direitos e são os únicos que podem utilizá-los, mas sempre com o consentimento do jogador, pelo que qualquer operação de transferência temporária ou definitiva dos direitos federativos necessita do consentimento do jogador (FILHO, 2008 e TERESA NADAL, 2008).

Alertamos para a importância de não se confundir o conceito de direito desportivo (federativo) com o de direito económico. O último, derivado do federativo, possui substância própria e é independente do primeiro, de tal maneira que a operação de venda do mesmo não necessita do consentimento do jogador (TERESA NADAL, 2008). Filho (2008, p. 36) definiu-o como "o contrato no qual o clube cede a um investidor os benefícios económicos 


\section{repec}

futuros, condicionais e aleatórios derivados da venda dos direitos federativos de um desportista". A venda parcial ou total do direito económico consiste num "reconhecimento a favor de terceiros de uma percentagem sobre a quantia da futura transferência do jogador ou sobre qualquer operação que se possa efectuar com os direitos económicos" (TERESA NADAL, 2008, p. 42). A principal finalidade da venda é, sem dúvida, que o clube receba capital antecipadamente à transferência do jogador para outro clube, mediante a cessão a determinados investidores de um crédito que está condicionado a um facto incerto - a efectiva transferência do direito desportivo sobre o jogador (TERESA NADAL, 2008). Como catalogou Filho (2008, p. 36), está-se perante uma "novel forma de oxigenação financeira dos clubes".

Em conclusão, o direito desportivo (federativo) e o direito económico são realidades completamente distintas, apesar de os seus titulares poderem coincidir. Analisa-se, seguidamente, a possibilidade de o direito desportivo sobre o jogador ser considerado como activo no balanço dos clubes detentores daquele direito.

\subsection{O direito desportivo sobre o jogador como activo}

A alínea a) do parágrafo (§) 49 da EC do IASB (2001) estabelece que activo "é um recurso controlado pela empresa como resultado de acontecimentos passados e do qual se espera que fluam para a empresa benefícios económicos futuros". Ou seja, o conceito de activo integra três componentes: controlo de um recurso; em resultado de acontecimentos passados; expectativa de geração de BEF. Em face da definição exposta, cabe concluir se o direito desportivo sobre um jogador será, ou não, um activo.

\subsubsection{Recurso económico controlado}

Para se determinar se um recurso é, ou não, controlado por dada entidade, deve-se ter em consideração a substância sobre a forma, a qual estabelece que as transacções e outros acontecimentos devem ser "contabilizadas e apresentados de acordo com a substância e realidade económica e não meramente com a sua forma legal" (IASB, 2001, §35). Assim sendo, a propriedade de um determinado bem não é condição necessária para que se esteja perante activos da entidade; basta que essa mesma entidade usufrua dos benefícios inerentes à utilização do bem ou do direito. Um bem ou direito é controlado por dada entidade sempre que esta estiver em condições de garantir a obtenção dos correspondentes BEF, independentemente da titularidade sobre o bem ou o direito.

No caso específico do direito desportivo sobre o jogador, podemos afirmar que este constitui um recurso económico do clube. A titularidade do direito desportivo por parte do clube confere-lhe o direito a usufruir os serviços a serem prestados pelo jogador, em resultado do contrato de trabalho celebrado com este, dos quais vão fluir para a organização benefícios económicos. Acresce que a referida titularidade confere ao clube não só a obtenção de benefícios, como a restrição do acesso aos mesmos por outros clubes, excepto 
selecções nacionais (MORROW, 1996). A natureza dos contratos de trabalho celebrados entre jogadores e clubes têm, pois, características particulares dado que o contrato celebrado entre as partes pode ser entendido como uma forma particular de controlo do clube sobre os benefícios produzidos pelo recurso humano, visto que durante o período de contrato o jogador apenas presta serviços de natureza desportiva ao clube ao qual está vinculado.

\subsubsection{Resultado de acontecimentos passados}

Outra condição é a necessidade de o objecto a valorizar provir de acontecimentos passados. Ou seja, é necessário que tenha existido uma transacção com o exterior ou que resulte da produção pela própria entidade. Quando o activo resulta da produção não ocorre uma única operação, como sucede numa aquisição, mas sim múltiplas operações relativas à aquisição dos vários factores cuja utilização origina distintos custos destinados ao desenvolvimento do processo (ORDOÑEZ SOLANA, 2001).

No caso de o jogador ser formado no próprio clube, também pode verificar-se a existência de acontecimento passado. A formação obriga que um clube incorra em gastos indispensáveis à formação do jogador, como, por exemplo, os relacionados com as observações efectuadas, com o treino e com os treinadores. Também o elemento "em resultado de acontecimentos passados", integrante do conceito de activo, é cumprido.

\subsubsection{Benefícios económicos futuros}

A EC do IASB (2001, §53) estabelece que:

Os benefícios económicos futuros num activo são o potencial de contribuir, directa ou indirectamente, para o fluxo de caixa e dos seus equivalentes de caixa para a empresa. O potencial pode ser um potencial produtivo que faça parte das actividades operacionais da empresa. Pode também tomar a forma de convertibilidade em caixa ou equivalentes de caixa ou a capacidade de reduzir os exfluxos de caixa, tais como quando um processo alternativo de fabricação baixe os custos de produção.

A expectativa de geração de benefícios futuros redunda, portanto, na probabilidade de gerar BEF, a qual resulta do ambiente de incerteza que caracteriza o mundo dos negócios e as actividades económicas (KAM, 1990).

A contribuição dos jogadores para o bom desempenho da equipa vai permitir o aumento dos fluxos de caixa do clube e dos correspondentes rendimentos. Quanto melhor o desempenho, maior a probabilidade de as receitas aumentarem, nomeadamente as de bilheteira, direitos televisivos, publicidade, merchandising, prémios monetários recebidos de instituições que organizam as competições em que participam. Acresce ainda, as que poderão ser obtidas pela alienação dos direitos desportivos sobre os jogadores antes do termo do contrato, ou, caso este já tenha expirado, se houver lugar a compensação por 
formação. Portanto, o direito desportivo sobre o jogador, e em particular o formado internamente, contribui para que fluam para o clube benefícios económicos. Concluímos, deste modo, que o direito desportivo sobre o jogador satisfaz o conceito de activo.

\section{TRATAMENTO CONTABILÍSTICO CONFERIDO PELOS CLUBES}

Na prática, tem-se assistido ao reconhecimento como activo intangível pelos clubes, no que respeita ao direito desportivo sobre o jogador. Porém, uma comparação entre o tratamento contabilístico dos clubes europeus com clubes brasileiros, permite-nos verificar que existe diferença a nível do direito desportivo resultante da formação.

\subsection{Europa}

Nos países europeus analisados, considera-se como activo intangível a aquisição a terceiros a título oneroso de direitos desportivos sobre os jogadores, conforme sintetizamos no Quadro 1.

Quadro 1 - Tratamento contabilístico dos direitos desportivos sobre jogadores por clubes europeus.

\begin{tabular}{|c|c|c|}
\hline País & Clube & $\begin{array}{l}\text { Informação recolhida do Anexo ao Balanço e à Demonstração } \\
\text { dos Resultados }\end{array}$ \\
\hline Escócia & Celtic $(2008$, p.36) & $\begin{array}{l}\text { "Os custos iniciais directamente atribuídos à aquisição }(\ldots) \text { do pessoal do } \\
\text { futebol são capitalizados e tratados como activos intangíveis.» }\end{array}$ \\
\hline França & $\begin{array}{l}\text { Olympique Lyonnais } \\
\quad(2008, \text { p. } 90)\end{array}$ & $\begin{array}{l}\text { "Os contratos relativos à aquisição de jogadores correspondem à definição } \\
\text { de um imobilizado incorpóreo. Eles são registados pelo custo de aquisição } \\
\text { actualizado se o diferimento do pagamento for superior a } 6 \text { meses.» }\end{array}$ \\
\hline Inglaterra & $\begin{array}{l}\text { Tottenham } \\
(2008, \text { p. } 38)\end{array}$ & $\begin{array}{l}\text { "Os custos associados com a aquisição dos direitos sobre os jogadores } \\
\text { (...) são capitalizados como activos fixos intangíveis.» }\end{array}$ \\
\hline \multirow{2}{*}{ Itália } & $\begin{array}{l}\text { Juventus } \\
(2008, \text { p. } 49)\end{array}$ & $\begin{array}{l}\text { "O direito plurianual à prestação dos jogadores é inscrito ao custo actua- } \\
\text { lizado, englobando as eventuais despesas acessórias.» }\end{array}$ \\
\hline & $\begin{array}{c}\text { Lázio } \\
(2008, \text { p. 33) }\end{array}$ & $\begin{array}{l}\text { "O saldo da rubrica "valor do plantel" inclui os custos associados à aqui- } \\
\text { sição dos direitos de inscrição desportiva dos jogadores.» }\end{array}$ \\
\hline \multirow[t]{2}{*}{ Portugal } & $\begin{array}{l}\text { Sporting SAD } \\
(2008, \text { p. } 46)\end{array}$ & $\begin{array}{l}\text { «Activos intangíveis e valor do plantel. Esta rubrica compreende os cus- } \\
\text { tos incorridos com a aquisição dos direitos desportivos dos jogadores pro- } \\
\text { fissionais de futebol (valor do plantel), e demais despesas relacionadas, } \\
\text { tais como comissões de intermediação e prémios de assinatura, líquidos } \\
\text { de amortizações acumuladas e perdas de imparidade.» }\end{array}$ \\
\hline & $\begin{array}{l}\text { Benfica SAD } \\
(2008, \text { p. } 46)\end{array}$ & $\begin{array}{l}\text { «Activos intangíveis (...) plantel de futebol. Esta rubrica compreende os cus- } \\
\text { tos incorridos com a aquisição dos direitos dos jogadores profissionais de } \\
\text { futebol a terceiros. O custo de aquisição compreende as importâncias des- } \\
\text { pendidas a favor da entidade transmitente, do jogador e de intermediários.» }\end{array}$ \\
\hline
\end{tabular}

Fonte: Elaboração própria 
Regra geral, verificamos que apenas os direitos desportivos adquiridos são reconhecidos como activos intangíveis no balanço dos respectivos clubes. Contudo, quanto aos direitos desportivos sobre os jogadores formados internamente, alguns clubes têm vindo a reconhecer no balanço valores relativos a esses jogadores. Por exemplo, os aumentos na rubrica "valor do plantel" verificados nas contas da Benfica, SAD de 2007 para 2008 foram justificados, entre outros aspectos, pelos «encargos com a renovação dos contratos dos atletas David Luiz, Miguel Victor, Romeu Ribeiro, Leonardo Bastos e Miguel Rosa» (BENFICA SAD, 2008, p. 67), sendo que os quatro últimos jogadores são jovens formados no clube. Porém, entendemos que tais encargos não correspondem aos gastos incorridos, no passado, com a formação de jovens atletas.

Concluímos, deste modo, que o direito desportivo sobre o jogador formado internamente não é reconhecido como activo intangível, tal como é o referente ao jogador adquirido a outro clube ou, quando o é, esse valor não traduz o custo de formação incorrido pelo clube nesse processo, mas o custo de aquisição do direito desportivo relativo a temporadas futuras.

Porém, o tratamento contabilístico dos direitos desportivos não é igual em toda a parte do mundo, como apresentamos de seguida para o caso particular do Brasil.

\subsection{Brasil}

Com a finalidade de comparar o tratamento contabilístico prestado pelos clubes europeus com o prestado pelos clubes brasileiros referente ao direito desportivo sobre o jogador, analisámos a informação contabilística disponibilizada nos websites dos clubes brasileiros que participaram na principal competição nacional no ano 2008 - Série A do Brasileirão -, por forma a existir uma comparabilidade temporal.

O Brasil tem vivido um período de convergência do respectivo normativo contabilístico às normas internacionais de contabilidade do IASB. Consequentemente, a partir do exercício económico 2008, o tratamento contabilístico dos activos intangíveis rege-se pela Norma Brasileira de Contabilidade Técnica (NBCT) n. 19.8 "Ativo Intangível”, aprovada pelo Conselho Federal de Contabilidade (CFC) em 2008, elaborada com base na IAS 38 do IASB.

Os clubes brasileiros, relativamente ao direito desportivo sobre o jogador, preparam e elaboram as DF não só de acordo com a NBCT n. ${ }^{0} 19.8$ (CFC, 2008), mas também com base na NBCT n. ${ }^{\circ} 10.13$ "Dos Aspectos Contábeis Específicos em Entidades Desportivas Profissionais" (CFC, 2004). Esta norma destinada às entidades desportivas estabelece "critérios e procedimentos específicos de avaliação, de registros contábeis e de estruturação das demonstrações contábeis das entidades de futebol profissional e demais práticas desportivas profissionais (...)" (CFC, 2004, §10.13.1.1).

$\mathrm{Na}$ quase totalidade dos aspectos focados para os clubes europeus, o tratamento contabilístico é igual para os clubes brasileiros, residindo a grande diferença ao nível do direito desportivo sobre o jogador formado internamente. Assim: 
Os valores gastos diretamente relacionados com a formação de atletas devem ser registrados no ativo imobilizado, em conta específica de formação de atletas. Quando da profissionalização do atleta, os custos devem ser transferidos para a conta específica de atleta formado, para amortização ao resultado do exercício pelo prazo contratual firmado (CFC, 2004, §10.13.2.3).

Com o objectivo de evitar a sobrevalorização dos activos, em consideração com a prudência necessária na preparação das demonstrações financeiras (DF), determinou:

No encerramento do exercício, no mínimo, deve ser avaliada a possibilidade de recuperação econômico-financeira do valor líquido contábil do custo de formação de cada atleta registrado no imobilizado. Constatada a irrecuperabilidade do custo, o valor deve ser baixado em conta específica do resultado, devendo estar suportada por documentação própria (CFC, 2004, §10.13.2.4).

A NBCT 10.13 (CFC, 2004) definiu um mecanismo de controlo dos encargos com a formação de jogadores, obrigando que as quantias capitalizadas sejam suportadas por um conjunto de informação mínimo.

Dos clubes brasileiros analisados, constatámos que, praticamente, a totalidade segue o normativo contabilístico referido (vide Quadro 2).

Quadro 2 - Tratamento contabilístico dos dispêndios com a formação de jogadores por clubes brasileiros.

\begin{tabular}{|c|l|}
\hline Clube & \multicolumn{1}{c|}{ Tratamento contabilístico } \\
\hline $\begin{array}{c}\text { Atlético Paranaense } \\
(2009)\end{array}$ & $\begin{array}{l}\text { Reconhece os valores despendidos com a formação de jogadores, bem como com a } \\
\text { aquisição dos direitos desportivos sobre os jogadores profissionais directamente em } \\
\text { contas do resultado. Esta prática valeu às contas do clube uma ressalva no Parecer } \\
\text { dos Auditores Independentes, dado que em relação a esta matéria as DF não tradu- } \\
\text { ziam adequadamente a posição patrimonial e financeira do clube. }\end{array}$ \\
\hline $\begin{array}{c}\text { Corinthians } \\
(2009)\end{array}$ & $\begin{array}{l}\text { O activo imobilizado em curso refere-se nomeadamente aos dispêndios com a for- } \\
\text { mação de jogadores amadores, que ao se tornarem profissionais são classificados } \\
\text { como activo intangível. }\end{array}$ \\
\hline $\begin{array}{c}\text { Coritiba } \\
(2009)\end{array}$ & $\begin{array}{l}\text { A rubrica "intangível" engloba o custo com formação de atletas, que representa os } \\
\text { custos incorridos com a manutenção das categorias de base da entidade e é com- } \\
\text { posto por custos de origem directa e indirecta, rateados conforme os critérios esta- } \\
\text { belecidos pela sua administração. Contudo, de acordo com o Parecer dos Auditores } \\
\text { Independentes as DF encerradas em 31 de Dezembro de 2008 não contemplam os } \\
\text { valores do investimento na formação de jogadores incorridos nesse ano, porque foi } \\
\text { totalmente reconhecido no resultado. }\end{array}$ \\
\hline
\end{tabular}




\begin{tabular}{|c|l|}
\hline $\begin{array}{c}\text { Fluminense } \\
(2009)\end{array}$ & $\begin{array}{l}\text { A rubrica "intangível" engloba o custo dos jogadores em formação, sobre o qual é } \\
\text { considerada no encerramento do exercício a possibilidade de recuperação económi- } \\
\text { co-financeira do valor líquido contabilístico de cada jogador em formação. Constata- } \\
\text { da que tal recuperação, parcial ou total, não se realizará, o valor é reduzido para o } \\
\text { seu valor recuperável ou o activo é desreconhecido. }\end{array}$ \\
\hline $\begin{array}{c}\text { Flamengo } \\
(2009)\end{array}$ & Os dispêndios com a formação de jogadores são tratados contabilisticamente de \\
acordo com a NBCT 10.13.
\end{tabular}

Fonte: Elaboração própria

Verifica-se, portanto, um tratamento diferenciado relativamente ao direito desportivo sobre o jogador formado internamente por parte dos clubes brasileiros em relação aos clubes europeus. Enquanto nestes últimos o direito desportivo sobre o jogador proveniente das camadas jovens ou não é reconhecido ou o é por um valor que não traduz o custo de formação, os clubes brasileiros reconhecem esse tipo de direito no activo, a título de activo intangível, pelo respectivo custo de formação. Note-se que, actualmente, em ambos os espaços geográficos as normas contabilísticas - IAS 38 e NBCT 19.8 - que regulam os activos intangíveis são idênticas e não proíbem que os dispêndios com a formação (treinamento), no caso de jogadores, sejam capitalizáveis, desde que se demonstre que se está perante um activo de natureza intangível e que as condições de reconhecimento como tal se encontram satisfeitas (CE, 2008 e CFC, 2008).

\section{PROBLEMA}

Como se verificou, nem todos os direitos desportivos sobre os jogadores que prestam serviços a um clube são reconhecidos no balanço, como os referentes a jogadores formados internamente. A grande questão reside em concluir se o dispêndio na formação de jovens jogadores pode, ou não, ser capitalizado no balanço do clube, questão que só se suscita relativamente aos jogadores cujo processo de formação tenha como consequência a sua inclusão na equipa principal do clube, pois só esses vão participar na actividade principal da entidade que os forma. 


\section{repec}

Independentemente da proveniência do jogador, o direito do clube em usufruir dos seus serviços enquadra-se no conceito de activo. Para o reconhecimento como activo intangível, devem ser preenchidas as seguintes condições, de acordo com a IAS n. ${ }^{\circ} 38$, "Activo Intangível", §21: "ser provável que os benefícios económicos futuros esperados que sejam atribuíveis ao activo fluam para a entidade"; e "o custo do activo possa ser fiavelmente mensurado" (CE, 2008).

A primeira condição considera-se suficientemente tratada. A segunda pode ser encarada, actualmente, como um entrave ao reconhecimento do direito desportivo sobre o jogador.

No caso da obtenção do direito pela formação interna não se estabelece uma transacção externa com outro clube para a sua aquisição. É certo que o processo de formação exige que se estabeleçam ao longo dos anos múltiplas operações. Mas como se poderão imputar individualmente esses custos? Necessita-se de um critério fiável para que o direito desportivo sobre o jogador se possa reconhecer no balanço do clube. A inexistência de uma transacção externa, para os intangíveis resultantes de um processo interno, é, em princípio, um entrave ao reconhecimento contabilístico do activo (ORDÓÑEZ SOLANA, 2001). A transacção externa é importante para que haja uma quantia monetária, conexa com o elemento patrimonial, que permita a sua mensuração.

Dado que os requisitos de reconhecimento como activo intangível não são verificados na totalidade, o direito desportivo sobre o jogador formado internamente não se reconhece no balanço, sendo todos os encargos com a formação reconhecidos na demonstração dos resultados como gasto do exercício em que ocorre. Esta é solução que tem sido adoptada em diversos países, pelo menos os europeus, em respeito à prudência. Porém, acreditamos ser possível alterar este cenário no futuro, tal como ocorreu no Brasil a partir do ano 2005.

\section{VALORIZAÇÃO DOS DIREITOS DESPORTIVOS RESULTANTES DA FORMAÇÃO}

Como verificámos é necessário prestar especial atenção aos critérios de valorização aplicáveis aos direitos desportivos sobre os jogadores profissionais, especificamente os formados nos próprios clubes. A problemática da valorização dos recursos humanos não é uma questão de hoje, mas de há muitos anos.

Trussel (1975) in Dobbins e Trussel (1975) aplicou, em 1974, os modelos do custo histórico, do custo de substituição e dos salários futuros descontados ajustados na valorização dos jogadores do Liverpool, apontando-os como uma solução para o problema da não valorização, na altura total, dos direitos desportivos sobre os jogadores.

Biagioni e Ogan (1977) apresentaram um modelo que consistia na valorização individual por jogador, independentemente do direito ter sido ou não adquirido ao exterior, por diversos avaliadores. O valor do direito desportivo sobre o jogador era determinado pela apreciação efectuada por cada avaliador ponderado pelo conhecimento que este tinha sobre o objecto em análise. 
Também os próprios clubes foram tentando ultrapassar a dificuldade de valorização. Por exemplo, na Inglaterra e na Escócia foram utilizadas algumas metodologias para valorizar os direitos desportivos, incluindo os resultantes da formação: multiplicador de rendimentos, avaliação de directores e avaliação múltipla independente (MORROW, 1995, 1996, 1997 e 1999).

Nos últimos anos, têm sido apresentados modelos para solucionar o problema apresentado. Ordóñez Solana (2001) propôs a determinação do custo de formação a capitalizar fazendo uso dos coeficientes de homogeneização. Moreno Rojas e Serrano Domínguez (2004) sugeriram a valorização dos direitos desportivos resultantes da formação com base nos valores de compensação por formação de jogadores estabelecidos pela FIFA. Seguidamente apresentamos um modelo alternativo para a valorização do direito desportivo sobre o jogador formado internamente.

\subsection{A formação de jogadores como analogia contabilística a actividades de investigação e desenvolvimento}

A IAS n. ${ }^{\circ} 38$ (CE, 2008) estabelece que as despesas de investigação são sempre de considerar como gasto no período em que incorrem. Numa fase inicial de um projecto é, frequentemente, difícil prever o seu sucesso. Em relação à actividade de desenvolvimento, as despesas incorridas só são capitalizáveis com a verificação conjunta de determinadas condições do normativo contabilístico, as quais visam assegurar que existe um elevado grau de probabilidade de obter benefícios futuros (CAÑIBANO CALVO, 1988).

$\mathrm{Na}$ primeira fase da formação de jovens jogadores - corresponde à actividade de investigação -, podem ser incluídas as actividades de observação levadas a efeito pelos "olheiros" dos clubes, bem como as primeiras épocas desportivas, que servem, sobretudo, para avaliar e desenvolver as capacidades dos jogadores. Nessa fase, são efectuadas as primeiras selecções. À medida que os jovens vão progredindo pelas diversas categorias, a selecção vai continuando, permanecendo no clube, apenas, os jogadores com maior probabilidade de servir a equipa principal - segunda fase do processo de formação, equiparável à actividade de desenvolvimento.

A transição da fase de investigação para a fase de desenvolvimento pode assentar numa das seguintes duas situações: a) Assinatura de um contrato de formação - válido para jogadores com idade compreendida entre os 14 e os 18 anos, conforme artigo $31 .^{\circ}$ da Lei n. ${ }^{\circ}$ 28/98, em Portugal (1998); b) Assinatura de um contrato profissional - só possível a partir dos 16 anos de idade, de acordo com o n. ${ }^{\circ} 1$ do artigo $4 .^{\circ}$ da Lei n. ${ }^{\circ} 28 / 98$, em Portugal (1998). A identificação do momento de início do desenvolvimento tem de assentar na menor incerteza quanto ao sucesso da formação do jogador e a uma elevada probabilidade de obtenção de BEF com os serviços deste. À medida que se avança no tempo, a incerteza é menor, pelo que, em nossa opinião, é mais adequado escolher o momento de celebração de um contra- 
to profissional como o da transição entre as duas fases da formação. A formalização deste contrato é o reconhecimento da parte do clube de que o jogador possui capacidades para prestar serviços na equipa profissional, contribuindo para o desenvolvimento da actividade da entidade, para o seu sucesso desportivo, consequentemente, para a obtenção de benefícios económicos. É certo que no momento da celebração do contrato não existe garantia da obtenção de BEF, mas a definição de activo refere-se quanto à expectativa de obtenção.

Os clubes não celebram, claro está, contratos profissionais com qualquer jogador formado internamente. Atente-se na transcrição que se segue:

A F. C. Porto - Futebol, SAD tinha, no início do exercício em análise, inscritos no activo da sociedade 74 atletas com contrato profissional. Destes (...) 43 respeitavam à Equipa $A, 22$ à Equipa $B$ e 9 aos Juniores $A$. Sublinhe-se que, no que respeita aos atletas que fazem parte dos Juniores $A$ e $B$, estrategicamente está definido que apenas se estabelece este vínculo com atletas que possuam qualidade para tal ou elevado potencial de desenvolvimento das suas capacidades (PORTO SAD, 2002, p. 8).

As condições de capitalização exigidas pela IAS n. ${ }^{\circ} 38$ (CE, 2008) podem ser preenchidas (vide Quadro 3) pela assinatura de um contrato profissional entre o jogador e o clube e através de uma reestruturação contabilística dos clubes, implementando um sistema de contabilidade analítica.

Quadro 3 - Preenchimento dos requisitos para a capitalização dos direitos desportivos sobre jogadores formados internamente.

\begin{tabular}{|c|c|c|}
\hline Âmbito & Requisitos da IAS 38 & Preenchimento dos requisitos \\
\hline Viabilidade & $\begin{array}{l}\text { Viabilidade técnica de concluir o activo intangível afim de } \\
\text { que esteja disponível para uso ou venda. }\end{array}$ & \multirow{4}{*}{$\begin{array}{l}\text { Celebração de um contrato profis- } \\
\text { sional entre o clube e o jogador. }\end{array}$} \\
\hline Finalidade & Intenção de concluir o activo intangível e usá-lo ou vendê-lo. & \\
\hline Mercado & Capacidade de usar ou vender o activo intangível. & \\
\hline $\begin{array}{l}\text { Benefícios } \\
\text { Económi- } \\
\text { cos } \\
\text { Futuros }\end{array}$ & $\begin{array}{l}\text { Forma como o activo intangível gerará prováveis BEF. En- } \\
\text { tre outros aspectos, a entidade pode demonstrar a exis- } \\
\text { tência de um mercado para a produção do activo intangí- } \\
\text { vel ou para o próprio activo intangível ou, se se destinar a } \\
\text { ser usado internamente, a utilidade do activo intangível. }\end{array}$ & \\
\hline Recursos & $\begin{array}{l}\text { Disponibilidade de adequados recursos técnicos, finan- } \\
\text { ceiros e outros para concluir o desenvolvimento e usar } \\
\text { ou vender o activo intangível. }\end{array}$ & Depende de cada clube. \\
\hline Valorização & $\begin{array}{l}\text { Capacidade para valorizar fiavelmente o dispêndio atribuível } \\
\text { ao activo intangível durante a sua fase de desenvolvimento. }\end{array}$ & $\begin{array}{l}\text { Utilização de um modelo assente } \\
\text { no custo histórico, com o apoio da } \\
\text { contabilidade analítica. }\end{array}$ \\
\hline
\end{tabular}

Fonte: Elaboração própria 
Em face do exposto, concluímos que se pode tratar o processo de formação de jogadores como equivalente, em termos contabilísticos, às actividades de I\&D. O principal obstáculo, como temos salientado, é a valorização fiável.

\subsection{Contributo da contabilidade analítica na determinação do custo de formação de um desportista}

Perante as dificuldades de valorização do direito desportivo sobre o jogador formado internamente propomos, seguidamente, um modelo baseado no custo histórico e com o apoio da contabilidade analítica. O objectivo é determinar o custo de formação de cada jogador profissional formado internamente, com base na valorização do consumo dos factores produtivos incorrido com as equipas das categorias de formação.

Com o auxílio da contabilidade analítica, que permite imputar custos a cada uma das actividades, obtém-se informação sobre o consumo dos recursos incorridos na formação de jogadores, de forma a valorizar fiavelmente os respectivos direitos desportivos.

\subsubsection{Custo de formação}

O valor do direito desportivo sobre o jogador formado internamente será dado pelo custo de formação, o qual deve representar os sacrifícios em que o clube incorreu para o formar e dotar das condições necessárias à prestação de serviços na equipa profissional.

A sua determinação parte do conceito de custo de produção. De forma simplificada, as matérias directas consumidas, a mão-de-obra directa e os custos indirectos de produção compõem o custo de produção. Transpondo esta noção para a formação de jogadores, o custo de formação tende a ser composto, essencialmente, pela mão-de-obra directa e por custos indirectos de produção. Considerando que a "matéria-prima" são os jovens jogadores, tem-se, principalmente, custos de transformação (mão-de-obra directa e custos indirectos de produção).

Entre os componentes a serem incluídos no custo de formação sobressaem os seguintes consumos: materiais desportivos, medicamentos e artigos de saúde, materiais sanitários, serviços externos (nomeadamente, comunicação, electricidade, água, gás, combustíveis, reparação e conservação, comissões, seguros, publicidade, rendas, deslocações e estadas, trabalhos especializados como os exames médicos necessários à prática desportiva) e os seguintes custos: pessoal (desportivo e não desportivo), arbitragem, policiamento, inscrição da equipa em competições, inscrição de jogadores, quotas pelo facto de a organização se encontrar inscrita em entidades desportivas (associações, federações), depreciações e juros suportados com empréstimos obtidos destinados exclusivamente à formação. Há, no entanto, que delimitar, com maior precisão, o período de capitalização. 


\section{repec}

\subsubsection{Delimitação do custo de formação a capitalizar}

De acordo com a Fédération Internationale de Football Association (FIFA, 2007, anexo 4 , artigo $1^{\circ},{ }^{\circ}{ }^{\circ}$ ), a formação de um jogador decorre no intervalo dos 12 aos 21 anos de idade. Uma das principais decisões a tomar reside no momento a partir do qual o custo de formação começa a ser originado. Uma hipótese passa por efectuar um segmento individualizado de cada jogador, desde o seu ingresso no clube. O seu acolhimento tem como consequência a capitalização dos gastos incorridos com a formação do jogador, mesmo antes do momento de celebração do contrato de profissional. Concluímos, deste modo, não ser possível adoptar esta hipótese, porque não respeita o disposto nas normas contabilísticas - estar-se-ia a capitalizar gastos incorridos na fase equiparada à "de investigação" do processo de formação. Para além do mais, a segmentação individualizada não parece viável, também, numa análise custo versus benefício. Como referiu Ordóñez Solana (2001), a complexidade administrativa deste procedimento desaconselha a sua utilização numa base de economicidade da informação contabilística.

Por outro lado, considerar cada jogador como equivalente a um projecto de I\&D em marcha não nos parece muito correcto, visto que muitos dos jogadores provenientes da formação não atingem o patamar desejado pelos clubes para que sejam considerados como possibilidades a integrar o plantel profissional do clube. O custo de formação deve, portanto, ser calculado considerando os encargos incorridos na formação do desportista, apenas, após a celebração do contrato profissional entre as partes.

Numa outra hipótese, o custo de formação pode englobar todos os encargos necessários relacionados com os jogadores envolvidos no mesmo processo de formação. Esta proposta justifica-se pelo facto de nenhum clube conseguir formar um jogador sem o contributo dos restantes. A formação supõe treinos e competição. Não é, com efeito, possível desenvolver as potencialidades de um jogador sem a participação de outros, ainda que vários participantes não venham a ser desportistas profissionais. O futebol é, como vários outros, um desporto colectivo, no qual a formação tem que ser efectuada em grupo.

A consideração não apenas dos jogadores com contrato como profissionais, mas de todos aqueles que permitiram o sucesso da formação dos que vêm a ser desportistas profissionais, justifica-se também pelas seguintes razões: inexistência de uma regra de proporcionalidade que garanta a obtenção de um jogador apto a ser profissional com base na preparação de um determinado número de jovens desportistas; e não ser possível definir qual a idade certa em que deve aparecer uma promessa desportiva, nem poder estabelecer-se de forma rigorosa um escalão desportivo como um período de aparição de jogadores com grau adequado de "excelência desportiva" (ORDÓÑEZ SOLANA, 2001). Como nem todos os custos incorridos 
pelo clube na formação de jogadores podem ser capitalizados, importa identificar a partir de que categoria de formação existe probabilidade razoável de o processo ter o sucesso desejado.

De acordo com as idades, os jogadores são inscritos nas respectivas categorias, definidas pelas respectivas Federações Nacionais. Tendo em consideração as categorias definidas pela Federação Portuguesa de Futebol (FPF, 2008), concluímos que: 1) os custos incorridos na categoria de escolas devem ser considerados totalmente como gastos do exercício, uma vez que nesta idade ainda não se iniciou o processo de formação de acordo com as normas desportivas; 2) as categorias de infantis e iniciados correspondem à fase de investigação de um processo de I\&D, pelo que os custos de formação, nessas idades, devem ser consideradas como gasto do exercício; 3) só a partir dos 16 anos é possível firmar contrato como profissional, ou seja, a partir da categoria de juvenis há a possibilidade de capitalizar custos de formação; 4) relativamente à categoria seniores, só se considera, na determinação dos custos de formação os que forem incorridos até à época em que o jogador completar 21 anos de idade, altura em que o processo de formação se encontra completo, de acordo com as normas desportivas. Em face do exposto, sintetizam-se as conclusões pertinentes no Quadro 4:

Quadro 4 - Proposta de tratamento contabilístico do investimento na formação de jogadores.

\begin{tabular}{|c|c|c|c|c|c|c|}
\hline Categoria & Escolas & Infantis & Iniciados & Juvenis & Juniores & $\begin{array}{c}\text { Seniores } \\
\text { (até } 21 \text { anos) }\end{array}$ \\
\hline $\begin{array}{l}\text { Regime contabi- } \\
\text { lístico proposto }\end{array}$ & $\begin{array}{l}\text { Gasto do } \\
\text { exercício }\end{array}$ & \multicolumn{2}{|c|}{$\begin{array}{l}\text { Por analogia com projecto } \\
\text { de I\&D: fase de investigação, } \\
\text { logo, gasto do exercício. }\end{array}$} & \multicolumn{3}{|c|}{$\begin{array}{l}\text { Por analogia com projecto de I\&D: fase de } \\
\text { desenvolvimento, logo, capitalizar a partir } \\
\text { da celebração do contrato profissional. }\end{array}$} \\
\hline
\end{tabular}

Fonte: Cruz (2006, p. 172)

Para este efeito, a utilização de um sistema de contabilidade analítica é, assim, necessário apenas a partir da categoria de juvenis e após celebrado o contrato profissional entre o jogador e o clube. Os gastos incorridos nas categorias anteriores não necessitam de controlo, pois não são capitalizáveis por corresponderem, por analogia, a actividades de investigação e porque mesmo que o jogador venha a celebrar um contrato como profissional, se tais dispêndios foram considerados, inicialmente, gastos de exercício não podem, posteriormente, ser capitalizados, de acordo com a IAS n. ${ }^{\circ}$ 38 (CE, 2008). Salientamos que, ainda de acordo com a norma, no caso de o custo de formação capitalizável ser superior ao valor expectável de recuperação será este último valor que constará no balanço do clube. Este teste de recuperabilidade (imparidade) deve ser efectuado pelo menos anualmente. 


\section{repec}

O incremento do custo de formação de determinado jogador termina na época em que completar 21 anos de idade, época a partir da qual o direito desportivo fica sujeito a amortização. De forma a valorizar o direito desportivo resultante da formação no balanço dos clubes, propomos um modelo de apuramento do custo de formação.

\subsubsection{Proposta de modelo de valorização}

Tendo presente a especificidade do problema em estudo, propomos um modelo de valorização para o direito desportivo sobre o jogador formado internamente. O modelo assenta no método dos centros de custo, porque este permite acumular os custos estritamente necessários na formação do jogador e um controlo sobre os respectivos centros. O modelo assenta nas seguintes etapas (vide Figura 1):

Figura 1: Etapas da valorização do direito desportivo sobre o jogador formado internamente, através da aplicação do método dos centros de custo.

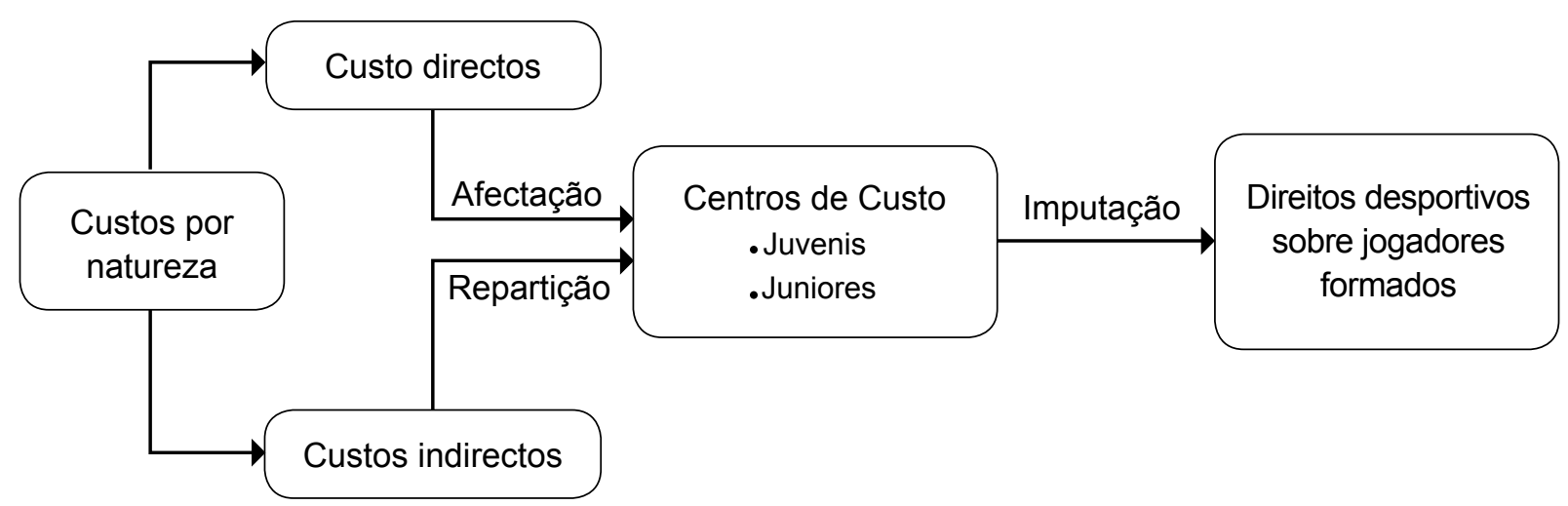

Fonte: Adaptado de Cruz (2006, p. 175)

Propomos dois objectos de custo: um principal - o direito desportivo sobre o jogador formado internamente; e um intermédio - centros de custo, constituídos pelas categorias que integram o processo de formação na fase equivalente à de "desenvolvimento". A classificação dos custos como directos ou indirectos depende do objecto de custo com o qual se relacionam. De forma a facilitar o apuramento do custo de formação sugerimos que todos os encargos a incluir no custo sejam afectados e, sempre que necessário repartidos, em primeiro lugar às categorias (vide Quadro 5), e só posteriormente imputados aos direitos desportivos sobre jogadores formados internamente. Pretende-se, deste modo, trabalhar com custos, na sua maioria, directos. Desta forma, minimiza-se a subjectividade presente na selecção de bases de repartição. Pode, naturalmente, ser necessário reestruturar procedimentos nos clubes. 
Quadro 5 - Custos directos e indirectos relativamente às categorias.

\begin{tabular}{|l|c|c|}
\hline \multicolumn{1}{|c|}{ Classificação de custos } & $\begin{array}{c}\text { Custos } \\
\text { directos }\end{array}$ & $\begin{array}{c}\text { Custos } \\
\text { indirectos }\end{array}$ \\
\hline Consumos de materiais desportivos & $\mathbf{X}$ & \\
\hline Consumos de medicamentos e artigos de saúde & $\mathbf{X}$ & \\
\hline Consumos de materiais sanitários & & $\mathbf{X}$ \\
\hline Consumos de serviços externos & $\mathbf{X}$ & $\mathbf{X}$ \\
\hline Pessoal desportivo & $\mathbf{X}$ & \\
\hline Pessoal não desportivo & $\mathbf{X}$ & $\mathbf{X}$ \\
\hline Arbitragem & $\mathbf{X}$ & \\
\hline Policiamento & $\mathbf{X}$ & \\
\hline Inscrição da equipa em competições oficiais & $\mathbf{X}$ & \\
\hline Inscrição de jogadores & & $\mathbf{X}$ \\
\hline Quotas pagas pela organização como filiada & & $\mathbf{X}$ \\
\hline Depreciações/Amortizações & $\mathbf{X}$ \\
\hline Juros suportados (relacionados com a formação) & & \\
\hline
\end{tabular}

Fonte: Adaptado de Cruz (2006, p. 178)

No Quadro 6, expomos os critérios de repartição dos custos indirectos pelos objectos de custo. De referir que alguns destes custos poderiam ser classificados como directos, dependendo da situação específica do clube.

Quadro 6 - Bases de repartição dos custos comuns pelos centros de custo.

\begin{tabular}{|l|l|}
\hline \multicolumn{1}{|c|}{ Natureza dos custos } & \multicolumn{1}{c|}{ Bases de repartição } \\
\hline Consumos de materiais sanitários & Número de treinos e jogos \\
\hline Consumos de serviços externos & \\
Rendas & Área ocupada (m2); Número de treinos e jogos \\
Seguros não desportivos & Número de equipas \\
Electricidade & Horas de treino e jogo \\
Água & Número de treinos e jogos \\
Gás & Número de treinos e jogos \\
\hline Pessoal não desportivo - departamento médico & Número de horas de tratamento efectivo \\
\hline Quotas pagas pela organização como filiada & Número de equipas inscritas \\
\hline Depreciações/Amortizações & Horas de utilização de equipamentos e estruturas \\
\hline Juros suportados (relacionados com a formação) & Número de equipas de formação \\
\hline
\end{tabular}

Fonte: Adaptado de Cruz (2006, p. 179)

Repartidos os custos comuns pelas respectivas categorias, determina-se o custo de formação anual de cada categoria, pelo somatório dos custos directos com os respec- 


\section{repec}

tivos custos indirectos. Para se conhecer o montante do direito desportivo sobre o jogador a ser acumulado existem três hipóteses de critério de imputação: 1) imputar ao direito desportivo apenas a fracção do custo total que corresponde ao formando; 2) imputar ao direito desportivo a totalidade do custo apurado na categoria a que o formando pertenceu durante a época desportiva; 3) imputar ao direito desportivo uma proporção do custo total apurado na categoria a que o formando pertenceu durante a época desportiva.

O conceito de custo de formação deve incluir os encargos estritamente necessários à formação do jogador; sendo o futebol um desporto colectivo, a primeira hipótese apontada não é apropriada, porque a formação de um jogador exige a participação de outros: a formação num desporto colectivo é, forçosamente, efectuada em grupo.

A questão que se suscita é saber quantos jogadores são necessários para formar um jogador profissional. A resposta a esta questão é fulcral para se optar pela segunda ou pela terceira hipótese. Na segunda, assume-se que todo o grupo é fundamental para a formação de um jogador profissional. Ou seja, independentemente do número de jogadores que compõem o grupo, devem ser considerados todos os encargos suportados com a formação do grupo. Neste caso, a imputação do custo total de formação dos centros de custo ao direito desportivo é completo, isto é, o custo é totalmente imputado ao direito desportivo sobre o jogador com contrato como profissional. Na terceira hipótese considera-se, no entanto, que a formação de um jogador requer a participação de outros jogadores, podendo, todavia, não ser necessário contemplar o custo com todos os jogadores da equipa, mas apenas uma parte. Só uma percentagem do custo total de formação seria imputada ao direito desportivo. A percentagem - elemento subjectivo - deve representar a relação entre o número de jogadores necessários para o desenvolvimento do processo de formação e o número de jogadores que compõem o grupo, os quais não são consensuais.

Entendemos que a imputação total do custo de formação de dado centro de custo ao direito desportivo relacionado é um critério mais objectivo. Acresce que o critério da imputação total dá relevo a aspectos que ultrapassam os que têm estritamente que ver com a capacidade técnica do formando, pois só considerando o grupo é possível atender a aspectos comportamentais na formação do jogador. Com efeito, o comportamento do desportista pode ser visto como variável decisiva no sucesso profissional, com reflexos na prestação do clube.

Concluímos, portanto, que o custo total de formação deve ser imputado na totalidade ao correspondente direito desportivo, ainda que apenas um formando, entre muitos outros, venha a assinar contrato como desportista profissional. Se suceder que dentro do mesmo processo de formação dois ou mais jogadores venham a outorgar contratos como profissionais, a imputação do custo total da formação efectuar-se-á em partes iguais pelos direitos desportivos sobre os jogadores formados. Reiteramos a ideia de que é necessário testar periodicamente a recuperabilidade dos valores capitalizados. 


\section{CONCLUSÕES}

O estudo pretendeu mostrar que o custo histórico, com o apoio da contabilidade analítica, é um critério de valorização aplicável aos direitos desportivos resultantes da formação, possibilitando, assim, o seu reconhecimento no Balanço dos clubes.

Se, por um lado, os direitos desportivos sobre jogadores estão em conformidade com o conceito de activo, por outro lado, as condições de reconhecimento como activo intangível nem sempre são plenamente satisfeitas. Em relação à probabilidade de fazerem fluir BEF para o clube não existem dúvidas: os jogadores são imprescindíveis nos resultados económicos do clube. Quanto melhor for o desempenho desportivo melhores tendem a ser os resultados económicos. Relativamente à exigência do custo ser valorizável com fiabilidade existem, porém, dificuldades no preenchimento da condição quando respeita a jogadores formados internamente.

No caso em análise, o custo de aquisição não se aplica, podendo, porém, adaptar-se a noção de custo de produção, que corresponde ao custo de formação. Com o objectivo de o calcular, consideramos que em termos contabilísticos, o processo de formação de jogadores equipara-se a actividades de I\&D, atentas as acentuadas incertezas envolvidas na formação. Os dispêndios com a primeira fase da formação devem ser considerados, na totalidade, como gastos do exercício no qual ocorrem. Na segunda fase da formação, celebrado o contrato como profissional entre o clube e o jogador estão reunidos os requisitos exigíveis para que os custos de formação sejam contabilizados como activo.

A valorização dos direitos recorre ao apoio da contabilidade analítica, na determinação do custo de formação. Como os encargos suportados com a formação só devem ser capitalizados a partir do momento da celebração de contrato como profissional, o que, em Portugal, somente pode ocorrer a partir dos 16 anos de idade, o sistema de contabilidade analítica só deve ser aplicado a partir da categoria de juvenis. Propomos um modelo assente no método dos centros de custo. O custo de formação de uma categoria deverá ser imputado proporcionalmente ao número de jogadores com contrato como profissional, pelo que, existindo um único, o custo de formação é imputável na totalidade ao respectivo direito desportivo.

A necessidade de seleccionar bases de repartição dos custos indirectos é uma limitação do modelo, dado que pode acarretar algum grau de subjectividade. Contudo, a restrição enunciada é superável pela relevância da informação, pois a informação dos direitos desportivos sobre jogadores adquiridos a terceiros é relevante. Naturalmente, a informação acerca dos direitos desportivos sobre os jogadores formados internamente também será de divulgar, pois em ambos os casos os jogadores prestam serviços de idêntica natureza e são factores valiosos do clube. Acresce que o reconhecimento dos 


\section{repec}

direitos desportivos resultantes da formação como activo, no balanço, é necessário para que a comparabilidade entre diferentes clubes seja possível.

Em trabalho futuro, será relevante aperfeiçoar o modelo apresentado e testá-lo em clubes que demonstrem abertura para o efeito, de forma a aferir sobre a sua viabilidade prática, com a finalidade de proporcionar uma solução que lhes permita a valorização dos direitos desportivos resultantes da formação e o seu reconhecimento no balanço.

\section{REFERÊNCIAS:}

ATLÉTICO PARANAENSE: CLUBE ATLÉTICO PARANAENSE. Relatório anual da Administração - exercício 2008. Paraná, 2008. Disponível em: http://www.atleticoparanaense.com/ anexos/Atletico-Balanco_2008-Publicacao_Diario_Oficial.pdf. Acesso em 28 ago. 2009.

BELL, J. Como realizar um projecto de investigação. $1^{\text {a }}$ Ed. Lisboa: Gradiva, 1997.

BENFICA SAD: SPORT LISBOA E BENFICA - FUTEBOL, SAD. Relatório \& Contas 2007/2008. Lisboa, 2008. Disponível em: http://www.slbenfica.pt/incslb/pdf/relatorioecontas_241008.pdf. Acesso em 28 ago. 2009.

BIAGIONI, L. F. e OGAN, P. Human resource accounting for professional sports teams. Management Accounting, Montlave, NJ, v. 59, n. 5, p. 25-29, 1977.

CAÑIBANO CALVO, L. Costes de investigacion y desarrollo. Madrid: Instituto de Contabilidad y Auditoria de Cuentas, 1988.

CE: Comissão Europeia. Regulamento (CE) n. ${ }^{0}$ 1126/2008 da Comissão, de 3 de Novembro de 2008: adopta determinadas normas internacionais de contabilidade nos termos do Regulamento (CE) n. ${ }^{\circ}$ 1606/2002 do Parlamento Europeu e do Conselho. Jornal Oficial da União Europeia L 320/1, de 29 de Novembro.

CELTIC PLC. Annual report: year ended 30 June 2008. Glasgow, 2008. Disponível em: http:// www.celticfc.net/NetFrame_Client/1_0_0/Pages/Displaylmage.aspx?resourcelD=84c71c529f96-4ef1-bada-e92d3c112289. Acesso em 28 ago. 2009.

CFC: CONSELHO FEDERAL DE CONTABILIDADE. Resolução CFC $\mathbf{n}^{\mathbf{0}} \mathbf{1 . 0 0 5 / 0 4}$ de 14 de Setembro de 2004: aprova a NBC T 10.13 - dos aspectos contábeis específicos em entidades desportivas profissionais. Brasília, DF. Disponível em: http://www.cfc.org.br/sisweb/ sre/detalhes_sre.aspx?Codigo=2004/001005. Acesso em 11 mar. 2009.

Resolução CFC n 1.139/08 de 21 de Novembro de 2008: aprova a NBC T 19.8 - Ativo intangível. Brasília, DF. Disponível em: http://www.cfc.org.br/sisweb/sre/docs/ RES_1139.doc. Acesso em 28 ago. 2009.

CORITBA FOOT BALL CLUB. Balanço de 2008. Coritiba, 2009. Disponível em: http://www. coritiba.com.br/arq/balanco_2008.pdf. Acesso em 28 ago. 2009. 
CORINTHIANS: SPORT CLUB CORINTHIANS PAULISTA. Demonstrações Financeiras referentes aos exercícios findos em 31 de Dezembro de 2008 e 2007. São Paulo, 2008. Disponível em: http://www.corinthians.com.br/site/clube/default.asp?categoria=Transparência. Acesso em 28 ago. 2009.

CRUZ, S. Direitos desportivos resultantes da formação: reconhecimento e mensuração. 2006. 215 p. Dissertação de Mestrado em Contabilidade e Auditoria - Departamento de Economia, Gestão e Engenharia Industrial, Universidade de Aveiro, Aveiro.

DOBBINS, R. e TRUSSEL, P. The valuation of human resources. Management Decision, London, v. 13, n. 3, p.155-169, 1975.

DOW JONES STOXX FOOTBALL INDEX. 30 January 2009. Disponível em: http://www. stoxx.com/download/indices/factsheets/djs_sports_fs.pdf. Acesso em 11 mar. 2009.

FLAMENGO: CLUBE DE REGATAS DO FLAMENGO. Relatório de gestão e balanço patrimonial. Rio de Janeiro, 2009. Disponível em: http://www.flamengo.com.br/site_clube/clube/balanco2008.pdf. Acesso em 28 ago. 2009.

FIFA: FÉDÉRATION INTERNATIONAL FOOTBALL ASSOCIATION. Regulations on the status and transfer of players. Zurich, 2007. Disponível em: http://www.fifa.com/mm/document/affederation/administration/regulations_on_the_status_and_transfer_of_players_ en_33410.pdf. Acesso em 28 ago. 2009.

FILHO, A. M. Reflexões em torno dos direitos federativos e econômicos. Derecho Deportivo En Línea, n. 10, p. 35-42, Septiembre 2007 - Marzo 2008. Disponível em: http://nuke.dd-el.com/ LinkClick.aspx?fileticket=AyMjNWK1sEQ\%3d\&tabid=60\&mid=396. Acesso em 28 ago. 2009.

FLUMINENSE FOOTBALL CLUB. Demonstrações Financeiras do exercício encerrado em 31 de dezembro de 2008 e 2007. Local, 2009. Disponível em: http://www.fluminense. com.br/_novo_/index2.asp. acesso em 22 abr. 2009.

FPF: FEDERAÇÃO PORTUGUESADE FUTEBOL. Comunicado oficial nº 1: época 2008/2009 - normas e instruções. Lisboa, 2008. Disponível em: http://www.fpf.pt/portal/page/portal/PORTAL_FUTEBOL/FEDERACAO/COMUNICADOS/CO1. Acedido em 11 mar. 2009.

GRÊMIO FOOT-BALL PORTO ALEGRENSE. Balanço financeiro 2008. Porto Alegre, 2009. Disponível em: http://www.gremio.net/upload/media/pagesite/balanço\%202008\%20publicação. pdf. Acesso em 28 ago. 2009.

IASB: INTERNATIONAL ACCOUNTING STANDARDS BOARD. The Framework for the Preparation and Presentation of Financial Statements. London, 2001.

JUVENTUS FOOTBALL CLUB, S.P.A. Relazioni e balancio 30 giugno 2008. Torino, 2008. Disponível em: http://www.juventus.com/site/filesite/finance/bilanci_relazioni/Bilancio_al_30_giugno_2008.pdf. Acesso em 28 ago. 2009. 


\section{repec}

KAM, V. Accounting Theory. 2nd ed. New York: John Wiley, 1990.

LAZIO: S. S. LAZIO, SPA. Balancio al 30 Giugno 2008. Roma, 2008. Disponível em: http:// www.sslazio.it/cms/view/home/societa_/investor_relator/s136. Acesso em 28 ago. 2009.

MORENO ROJAS, J. e SERRANO DOMÍNGUEZ, F. Contabilidad de recursos humanos cuando existen restricciones a la movilidad laboral: propuesta de revelación de información en clubes profesionales de fútbol. Estudios Financieros. Revista de Contabilidad y Tributación, Madrid, n. 257-258, p. 219-240, 2004.

Modelos de valoración de derechos sobre deportistas profesionales: revisión crítica de la literatura y propuestas de actuación. Estudios Financieros. Revista de Contabilidad y Tributación, Madrid, n. 272, p. 157-196, 2005.

MORROW, S. Recording the human resource of football players as accounting assets: establishing a methodology. The Irish Accounting Review, Dublin, v. 2, n. 1, p. 115-132, 1995.

Football players as human assets: measurement as the critical factor in asset recognition: a case study investigation. Journal of Human Resource Costing and Accounting, Bradford, v. 1, n. 1, p. 75-97. Spring, 1996.

Accounting for football players: financial and accounting implications of 'Royal Club Liégois and others $V$ Bosman' for football in the United Kingdom. Journal of Human Resource Costing and Accounting, Bradford, v. 2, n. 1, p. 55-71, Spring, 1997.

The new business of football - accountability and finance in football. New York: Palgrave Macmillan, 1999.

OLYMPIQUE LYONNAIS GROUPE. Rapport financier annuel 07-08. Lyon, 2008. Disponível em: http://www.actusnews.com/documents_communiques/ACTUS-0-14077-OLGroupe_Rapport_Annuel_2007-2008.pdf. Acesso em 28 ago. 2009.

ORDÓÑEZ SOLANA, C. Reconocimiento contable de jugadores en empresas que participan en competición profesional. 2001. 587 p. Tesis Doctoral. Universidad Granada,. Departamento de Economía Financiera y Contabilidad, Facultad de Ciencias Económicas y Empresariales, Universidad de Granada, Granada.

PORTO SAD: FUTEBOL CLUBE DO PORTO - FUTEBOL, SAD. Relatório e Contas Consolidado 2001/2002. Porto, 2002. Disponível em: http://www.fcporto.pt//ncFCP/PDF/Investor_Relations/RelatoriosContas/RelatorioConsolidado_20012002.pdf. Acesso em 28 ago. 2009.

Relatório e contas 2007/2008. Porto, 2008. Disponível em: http://www.fcporto.pt/ IncFCP/PDF/Investor_Relations/RelatoriosContas/RCIndividual20072008.pdf. Acesso em 28 ago. 2009.

PORTUGAL. Lei n 28/98, de 26 de Junho de 1998. Regime jurídico do contrato de trabalho desportivo e do contrato de formação desportiva. Diário da República, Lisboa, I Série-A, n. ${ }^{\circ} 145,1998$. 
RODRIGUES, F. X. F. Direitos federativos, negociações de jogadores e flexibilização de contratos de trabalho no futebol brasileiro. Em 1..$^{\circ}$ Encontro da ALESDE - Esporte na América Latina: atualidade e perspectivas, Curitiba - Paraná, 30 de Outubro a 1 de Novembro de 2008. Disponível em: http://www.alesde.ufpr.br/encontro/trabalhos/45.pdf. Acesso em 28 ago. 2009.

SANTOS FUTEBOL CLUBE. Balanço patrimonial do exercício 2008. Santos, SP, 2009. Disponível em: http://santos.globo.com/arquivos/arq_321_SANTOS_JORNAL.pdfAcesso em 28 ago. 2009.

SÃO PAULO FUTEBOL CLUBE. Balanço 2008. São Paulo, 2009. Disponível em: http:// www.saopaulofc.net/spfc/balanco/2008.pdf. Acesso em 28 ago. 2009.

SPORTING SAD: SPORTING - SOCIEDADE DESPORTIVA DE FUTEBOL, SAD. Relatório e contas da Sporting SAD: época 2007/2008. Lisboa, 2008. Disponível em: http:// www.sporting.pt/incsporting/pdf/investor_relations/RelatorioContas20072008.pdf. Acesso em 28 ago. 2009.

TERESA NADAL, M. Un acercamiento a los derechos federativos y su contenido patrimonial. Iuris, Madrid, n. 128, Junio, 40-43, 2008.

TOTTENHAM HOTSPUR, PLC. Annual report 2008. London, 2008. Disponível em: http:// www.tottenhamhotspur.com/uploads/assets/docstore/2008_annual_report.pdf. Acesso em 28 ago. 2009. 